\title{
Association between hepatoblastoma and polyposis coli
}

\author{
J E KINGSTON, A HERBERT, G J DRAPER, AND J R MANN \\ Childhood Cancer Research Group, Department of Paediatrics, University of Oxford, \\ Wessex Regional Cytogenetics Unit, Salisbury, Wiltshire, and \\ The Children's Hospital, Ladywood, Birmingham
}

SUMMARY We have identified five children with hepatoblastoma who have a family history of polyposis coli affecting the mother and maternal relatives. We believe that the familial association of these two conditions is unlikely to have occurred by chance. Cytogenetic studies on three of the families have shown no evidence of a chromosomal abnormality.

Hepatoblastoma is a rare tumour affecting about $1 / 100000$ children under the age of 15 years. $^{1}$ Polyposis coli is another uncommon condition with an estimated incidence of approximately $1 / 8000$ births. ${ }^{2}$ We have previously reported a possible association between hepatoblastoma and polyposis coli. $^{3}$ In the United Kingdom one case of polyposis coli occurring in the mother of a child with hepatoblastoma would be expected in about 1000 years. We describe five such cases occurring during a period of 50 years.

\section{Patients and methods}

Three of the five children were identified during a review of the records of 113 cases of hepatoblastoma registered with the Childhood Cancer Research Group during the period 1962-1975. A further two 'anecdotal' cases were notified to us by clinicians

Table Details of the five children all of whom had complete surgical resection of the hepatoblastoma

\begin{tabular}{|c|c|c|c|c|c|}
\hline Case No & Sex & $\begin{array}{l}\text { Year of } \\
\text { diagnosis }\end{array}$ & $\begin{array}{l}\text { Age at } \\
\text { diagnosis } \\
\text { (months) }\end{array}$ & Status & $\begin{array}{l}\text { Cause of } \\
\text { death }\end{array}$ \\
\hline 1 & $\mathbf{M}$ & 1975 & 21 & Dead & $\begin{array}{l}\text { Intestinal } \\
\text { obstruction } \\
2^{\circ} \text { to } \\
\text { adhesions }\end{array}$ \\
\hline 2 & $\mathbf{F}$ & 1974 & 7 & Alive & - \\
\hline 3 & $\mathbf{M}$ & 1973 & 24 & Alive & 一 \\
\hline 4 & $\mathbf{M}$ & 1963 & 14 & Dead & $\begin{array}{l}\text { Acute } \\
\text { distension of } \\
\text { small bowel }\end{array}$ \\
\hline 5 & $\mathbf{M}$ & 1926 & 24 & Dead & $\begin{array}{l}\text { Haemorrhage } \\
\text { in post- } \\
\text { operative } \\
\text { period }\end{array}$ \\
\hline
\end{tabular}

aware of our interest in the subject. Details of the five children are given in the Table and the family pedigrees are outlined in Figs. 1-5.

\section{Histological review}

Histological sections of the tumours of these five patients have been reviewed and in all cases the tumour was a typical hepatoblastoma, described as well differentiated in four patients and moderately well differentiated in the fifth. A distinct lobular pattern was present in four of the tumours and in

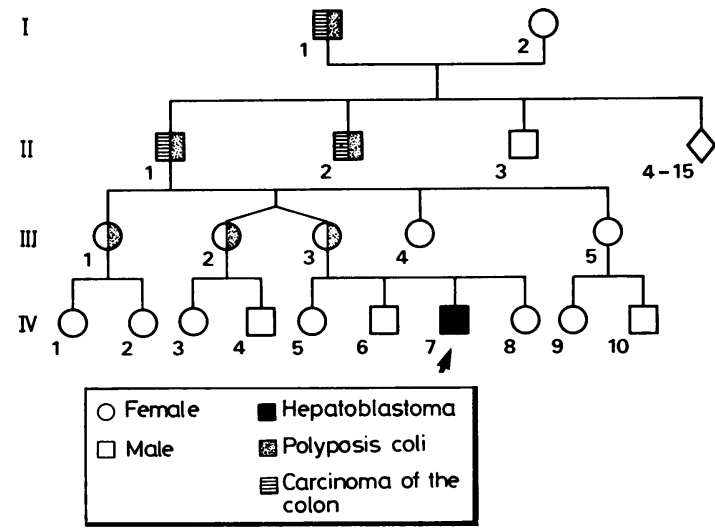

Fig. 1 Pedigree of case 1-arrow indicates proband. The child's mother has polyposis coli diagnosed at the age of 25 years. Two maternal aunts also have polyposis coli. The maternal grandfather, great grandfather and great uncle all died of carcinoma of the colon at relatively young ages and are therefore presumed to have had polyposis coli. 
three apparent encapsulation was a prominent feature. There were, however, no specific histological features to distinguish these tumours from cases of hepatoblastoma with no family history of polyposis coli.

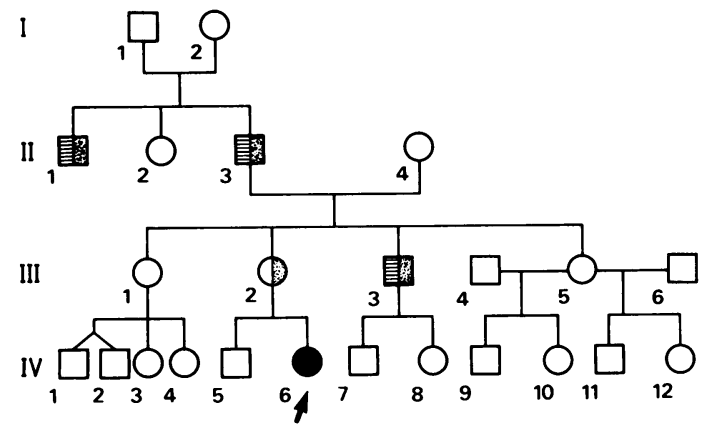

\begin{tabular}{|ll|}
\hline $\begin{array}{l}\text { O Female } \\
\square \text { Male }\end{array}$ & $\begin{array}{l}\text { 目 Hepatoblastoma } \\
\text { Polyposis coli } \\
\text { Carcinoma of the } \\
\text { colon }\end{array}$ \\
\hline
\end{tabular}

Fig. 2 Pedigree of case 2-arrow indicates proband. The mother of the proband has polyposis coli diagnosed at the age of 32 years. The maternal grandfather and a maternal uncle both had polyposis coli and died of carcinoma of the colon aged 27 years and 31 years respectively. A maternal great uncle died of a bowel cancer at a relatively young age and it is presumed that he also had polyposis coli.

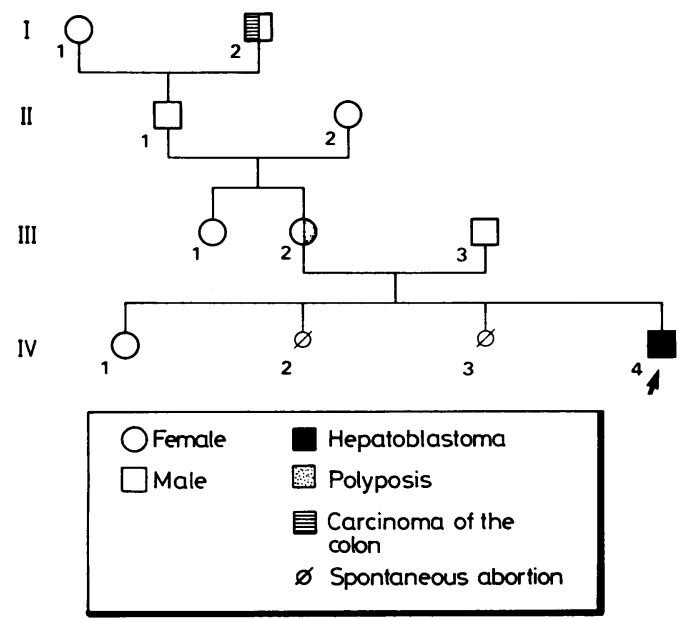

Fig. 3 Pedigree of case 3-arrow indicates proband. His mother was diagnosed with polyposis coli at the age of 28 years. The maternal great grandfather died of carcinoma of the colon.

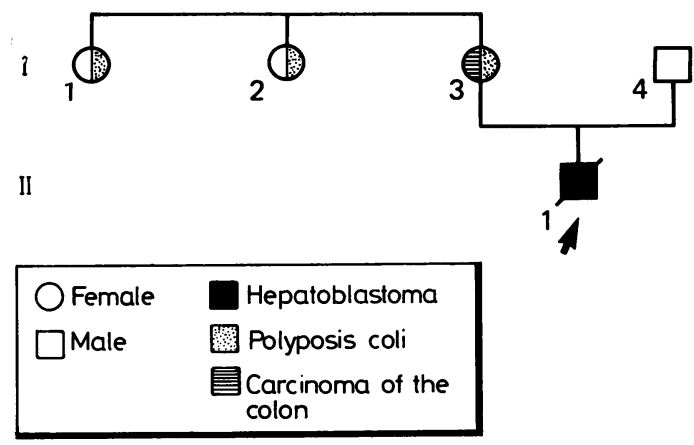

Fig. 4 Pedigree of case 4-arrow indicates proband. This child's mother and two maternal aunts had polyposis coli. The mother died of metastatic carcinoma of the colon shortly after the death of her son.

\section{Cytogenetic studies}

Detailed cytogenetic analyses were carried out on chromosomes cultured from peripheral blood lymphocytes of the three mothers with polyposis coli who are still alive and of the two surviving children. High resolution banding of extended prometaphase preparations, giving approximately 1000 bands per haploid karyotype, was done using the method described by Herbert. ${ }^{4}$

\section{Results}

Cytogenetic analysis. The high resolution banding studies of prometaphase chromosome preparations in the three surviving mothers with polyposis coli failed to show any evidence of a consistent deletion or heteromorphism that could not be attributed to the natural phenomenon of 'lag' in condensation of G negative chromatin which is evident between homologous chromosomes in extended preparations. Similarly, no abnormality was detected in the two surviving children with hepatoblastoma. We found no evidence of aneuploidy in any of the patients investigated.

Statistical analysis. The original three cases described in this paper were found among a series of 113 cases notified to the Childhood Cancer Research Group for the period 1962-75. These notifications were all derived from the National Cancer Registration Scheme and probably represent at least $80-90 \%$ of all cases of hepatoblastoma occurring in Britain during that period.

Varying estimates of the incidence of polyposis coli have been given but it is probably about $1 / 8000 .^{2}$ Thus the frequency of mothers with polyposis coli in our series of hepatoblastomas, $3 / 113$, is approximately 200 times that in the general population. In 


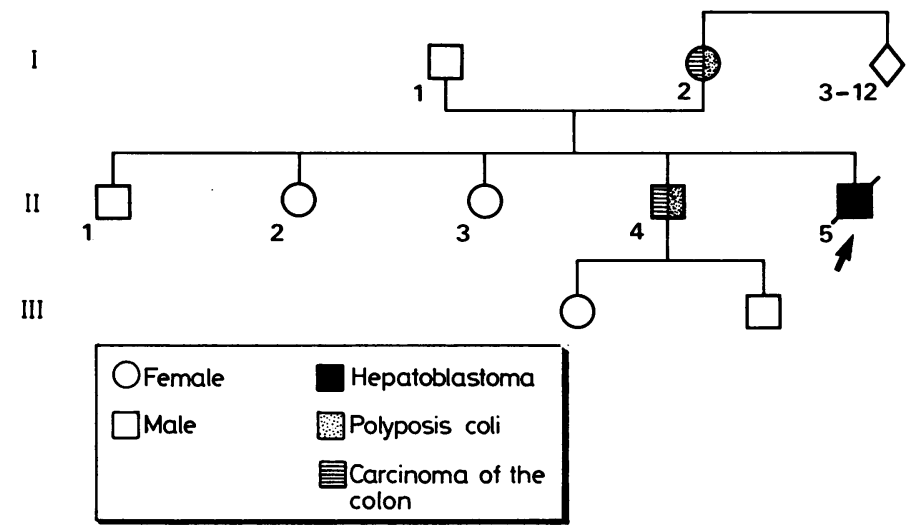

Fig. 5 Pedigree of case 5-arrow indicates proband. The child's mother and brother had polyposis coli: both died from carcinoma of the colon. Four of the mother's 10 siblings were also affected with polyposis coli. The brother had a cyst on his thigh and abnormal dentition, probable manifestations of Gardner's syndrome.

Britain about 8 cases of hepatoblastoma occur each year; thus if there were no real association between hepatoblastoma and maternal polyposis coli the type of association reported here would be expected to occur in Britain only once every 1000 years. (If we regard the association as relating to the parents rather than to just the mother it is more appropriate to make comparisons with the chance of polyposis coli occurring in either parent-that is $1 / 4000$. Our findings are then that polyposis coli occurs 100 times more frequently among the parents of children with hepatoblastoma than among parents generally and that such an association would be expected to occur in Britain only once every 500 years).

The probability that any three mothers among a group of 113 have a disease with a frequency as low as that of polyposis coli, is about $1 / 2$ million; the probability that either the mother or father will be affected in three cases is about $1 / 250000$. This does not mean, however, that we can state that the association is statistically significant at one of these levels. It is not possible to carry out a valid statistical test since we did not set out to analyse our data for any specific association; in calculating a significant level we should take into account the fact that even if there were no real disease association with hepatoblastoma, we might have observed any one of a large number of possible disease associations purely by chance. Unfortunately, there seems to be no satisfactory way of quantifying this in the present instance. We suggest, however, particularly in view of the two additional 'anecdotal' cases reported here and the fact that children whose mothers had polyposis coli seem to have a particularly good prognosis, that the most reasonable explanation of our findings is that there is a true association between hepatoblastoma and maternal polyposis coli.

\section{Discussion}

Hepatoblastoma has been reported in association with hemihypertrophy, Wilms' tumour, ${ }^{5}$ the Wiedemann-Beckwith syndrome, ${ }^{6}$ and the fetal alcohol syndrome. ${ }^{7}$ There have also been occasional reports of sibship aggregations of hepatoblastoma. ${ }^{8}$ There have been two previous reports of intestinal polyposis in maternal relatives of children with hepatoblastoma. ${ }^{9}{ }^{10}$ One of these reports ${ }^{9}$ almost certainly referred to the patient in case 5 . In addition, in an epidemiological study of 356 cases of primary carcinoma of the liver in childhood, ${ }^{11}$ neoplasia was reported among the parents of three cases; breast cancer in two mothers, and intestinal polyposis in one father.

Various conditions are known to occur in association with polyposis coli. In 1962 Gardner $^{12}$ described a group of polyposis coli patients with a cluster of benign extra colonic manifestations including osteomas of the cranium and mandible with overlying fibromata, abnormal dentition, sebaceous or epidermoid cysts on the back, and, occasionally, mesenteric fibromatosis. Other extracolonic neoplasms that have been described in patients with Gardner's syndrome include periampullary cancer, ${ }^{13}$ bile duct cancer, ${ }^{14}$ gastric and duodenal polyposis, ${ }^{15}$ papillary thyroid cancer, ${ }^{16}$ and desmoid tumours. ${ }^{17}$ In 1981 , Weinberger ${ }^{18}$ reported the case of a 20 year old woman with polyposis coli who had a past history of an hepatocellular carcinoma which had been successfully resected at the age of $3 \frac{1}{2}$ years. In the same year, Greenberg et al..$^{19}$ described acute myelocytic leukaemia occurring as a second malignancy in two brothers with polyposis coli and carcinoma of the colon.

During the past decade some cases of retinoblastoma and Wilms' tumour, two other embryonal 
tumours of childhood, have been found to be associated with specific chromosomal deletions. Gardner has reported a consistent heteromorphism of chromosome no $2(2 \mathrm{q} 21 \cdot 3)$ in 17 patients with multiple adenomas of the colorectum..$^{20}$ Therefore, in our initial report of the association between hepatoblastoma and polyposis coli, ${ }^{3}$ we considered it possible that a chromosomal abnormality, such as a deletion, might be found in some patients with hepatoblastoma, particularly in those children who had a family history of polyposis coli. As yet, however, we have not succeeded in identifying any structural chromosomal abnormality in the three families that have been studied.

All five of the children had well or moderately well differentiated tumours; which were completely resectable. Three of the five children are considered to have died from complications of surgery rather than recurrent hepatoblastoma. As polyposis coli is inherited as an autosomal dominant condition, the two surviving children with hepatoblastoma have a $1 / 2$ chance of developing polyposis coli and will need to be screened regularly.

In summary, the present report describes five children with hepatoblastoma all of whom have a history of polyposis coli affecting the mother. In four of the children, one or more of the maternal relatives is also known to have had polyposis coli. One of the five children, case 5 , is believed to have been included in a previous report describing the outcome of children with hepatic tumours. ${ }^{9}$ The additional four cases thus brings the number of reported cases of hepatoblastoma occurring in children with a family history of polyposis coli to a total of 7 . For reasons explained above, we consider that the association of these two conditions is unlikely to have occurred by chance.

We thank Mr J J Corkery, Dr R E Olver and Dr J L Pearce for permission to publish details about their patients; $\mathrm{Mr}$ W Cochran for notifying us and providing details of case 4; Dr H J R Bussey, Consulting Research Fellow at St Mark's Hospital for his helpful discussion on various aspects of polyposis coli and for details of case 5; Dr L M Kinnier Wilson for her assistance in obtaining family histories of children with liver tumours and $\mathrm{Dr} A \mathrm{H}$ Cameron for reviewing the histopathology of the tumours; the OPCS; the Scottish Home and Health Department; and the Regional Cancer Registeries.

JEK is a research fellow in the Department of Paediatrics at Oxford University and is supported by the Cancer Research Campaign. The Childhood Cancer Research Group is supported by the Department of Health and Social Security and the Scottish Home and Health Department.

\section{References}

1 Draper GJ, Birch JM, Bithell JF, et al. Childhood cancer in Britain: incidence, survival and mortality. (Studies on medical and population subjects no 37). London: HMSO, 1982.

2 Reed TE, Neel JV. A genetic study of multiple polyposis of the colon. AmJ Hum Genet 1955;7:236-63.

${ }^{3}$ Kingston JE, Draper GJ, Mann JR. Hepatoblastoma and polyposis coli (letter). Lancet $1982 ; \mathbf{i}: 457$.

4 Herbert A. High resolution banding of prometaphase chromosomes. Hum Genet 1982;61:63-4.

5 Fraumeni JF, Jr, Geiser CF, Manning MD. Wilms' tumour and congenital hemihypertrophy. Report of five new cases and review of literature. Pediatrics 1967;40: 886-99.

6 Moncrieff MW, Mann JR, Goldsmith AR, Chance GW. Macroglossia, abnormal umbilicus and hypoglycaemia (Beckwith's syndrome). Postgrad Med J 1970;46:162-6.

7 Khan A, Bader JL, Hoy GR, Sinks LF. Hepatoblastoma in child with fetal alcohol syndrome (letter). Lancet $1979 ; \mathbf{i}: 1403-4$.

8 Fraumeni JF, Jr, Rosen PJ, Hull EW, Barth RF, Shapiro SR, O'Connor JF. Hepatoblastoma in infant sisters. Cancer 1969;24:1086-90.

9 McNab GH, Moncrieff AA, Bodian M. Primary malignant hepatic tumours in childhood. British Empire Cancer Campaign 30th Annual Report 1952;168-76.

10 Berhle FC, Mantz FA, Jr, Olson RL, Trombold JC. Virilization accompanying hepatoblastoma. Pediatrics $1963 ; 32: 265-71$.

11 Fraumeni JF, Jr, Miller RW, Hill JA. Primary carcinoma of the liver in childhood. An epidemiologic study. Journal of the National Cancer Institute 1968;40:1087-99.

12 Gardner EJ. Follow up study of a family group exhibiting dominant inheritance for a syndrome including intestinal polyps, osteomas, fibromas and epidermal cysts. Am J Hum Genet 1962;14:376-90.

13 MacDonald JM, Davis WC, Crago HR, Berk AD. Gardner's syndrome and periampullary malignancy. Am J Surg 1967;113:425-30.

14 Lees CD, Hermann RE. Familial polyposis coli associated with bile duct cancer. Am J Surg 1981 ;141:378-80.

15 Hoffmann, DC, Goligher JC. Polyposis of the stomach and small intestine in association with familial polyposis coli. Br J Surg $1971 ; 58: 126-8$.

16 Camiel MR, Mule JE, Alexander LL, Benninghoff DL. Association of thyroid carcinoma with Gardner's syndrome in siblings. $N$ Engl J Med 1968;278:1056-8.

17 Smith WG. Multiple polyposis, Gardner's syndrome and desmoid tumors. Dis Colon Rectum 1958;1:323-32.

18 Weinberger JM, Cohen Z, Berk T. Polyposis coli preceded by hepatocellular carcinoma. Report of a case. Dis Colon Rect $1981 ; 24: 296-300$.

19 Greenberg MS, Anderson KC, Marchetto DJ, Li FP. Acute myelocytic leukemia in two brothers with polyposis coli and carcinoma of the colon. Ann Intern Med 1981; 95:702-3.

20 Gardner EJ, Rogers SW, Woodward S. Numerical and structural chromosome aberrations in cultured lymphocytes and cutaneous fibroblasts of patients with multiple adenomas of the colorectum. Cancer 1982;49:1413-9.

Correspondence to Dr J E Kingston, Clinical Research Fellow, Childhood Cancer Research Group, Radcliffe Infirmary, Woodstock Road, Oxford.

Received 5 September 1983 